\title{
ADUBAÇÃO COM URÉIA E SULFATO DE AMÔNIO NO MILHO CULTIVADO SOB SISTEMA SEMEADURA DIRETA
}

\author{
COUTINHO NETO, André Mendes ${ }^{1}$ \\ COUTINHO, Edson Luiz Mendes ${ }^{2}$ \\ ORIOLI JÚNIOR, Valdeci ${ }^{3}$ \\ CORÁ, José Eduardo ${ }^{2}$ \\ BUENO, Célia Regina Paes ${ }^{2}$ \\ SILVA, Alysson Roberto Baizi $\mathrm{e}^{4}$
}

RESUMO: O objetivo deste trabalho foi avaliar a influência de doses e fontes de nitrogênio nas concentrações foliares e na produtividade de grãos de milho, cultivado em sistema semeadura direta, num solo argiloso (Latossolo Vermelho distroférrico) com baixo teor de enxofre. As doses de N (0, 50, 100, 150 e $200 \mathrm{~kg}$ $\mathrm{ha}^{-1}$ ) foram aplicadas na forma de uréia e sulfato de amônio. A adubação nitrogenada aumentou significativamente as concentrações de $\mathrm{N}$ nas folhas e a produtividade de grãos de milho. Para essas variáveis, a uréia e o sulfato de amônio apresentaram um comportamento semelhante. Sintomas de deficiência de $\mathrm{N}$ foram observados quando as plantas apresentavam concentrações desse nutriente inferiores a $23,0 \mathrm{~g} \mathrm{~kg}^{-1}$. As concentrações de $\mathrm{N}$ nas folhas, consideradas adequadas, estiveram dentro dos limites de 28,0 a $31,9 \mathrm{~g} \mathrm{~kg}^{-1}$.

Palavras-chave: Deficiência nutricional. Enxofre. Nitrogênio. Nível crítico. Zea mays.

\section{FERTILIZATION WITH UREA AND AMMONIUM SULFATE IN MAIZE UNDER NO-TILLAGE SYSTEM}

SUMMARY: The objective of this work was to evaluate the influence of rates and nitrogen sources on leaves nutrient contents and maize yield. The maize was cultivated under no-tillage system, in a clayey soil (Typic Acrustox) with low content of sulfur. Urea and ammonium sulfate were applied at the rates of $\mathrm{N}(0,50,100,150$, and $200 \mathrm{~kg} \mathrm{ha}^{-1}$ ). The $\mathrm{N}$ fertilization increased significantly the concentrations of $\mathrm{N}$ in the leaves and the maize yield. For those variables, the urea and the ammonium sulfate presented a similar behavior. Symptoms of deficiency of $\mathrm{N}$ were observed when the plants presented leaves $\mathrm{N}$ concentrations lower than $23 \mathrm{~g} \mathrm{~kg}^{-1}$. The sufficient contents of $\mathrm{N}$ in the leaves ranged from 28.0 to $31.9 \mathrm{~g} \mathrm{~kg}^{-1}$.

Keywords: Critical level. Nitrogen. Nutritional deficiency. Sulfur. Zea mays.

\section{INTRODUÇÃO}

O N é constituinte de vários compostos em plantas, destacando-se os aminoácidos, ácidos nucléicos e clorofila. Assim, as principais reações bioquímicas em plantas e

\footnotetext{
${ }^{1}$ Mestrando do Curso de Pós-Graduação em Ciência do Solo. Faculdade de Ciências Agrárias e Veterinárias (FCAV), UNESP - Universidade Estadual Paulista, Campus de Jaboticabal. Bolsista do CNPq.

${ }^{2}$ Professor Doutor. FCAV, UNESP, Campus de Jaboticabal, Departamento de Solos e Adubos. E-mail: coutinho@fcav.unesp.br

${ }^{3}$ Doutorando do Curso de Pós-Graduação em Produção Vegetal. FCAV, UNESP, Campus de Jaboticabal. Bolsista da CAPES.

${ }^{4}$ Doutor em Agronomia. Bunge Brasil.
} 
microrganismos envolvem a presença do $\mathrm{N}$, o que o torna um dos elementos absorvidos em maiores quantidades por plantas cultivadas (EPSTEIN; BLOOM, 2006). Vários trabalhos têm demonstrado que para a cultura do milho, a adubação nitrogenada é um dos fatores de produção mais importante na busca de aumentos na produtividade de grãos, embora, constitua-se também, no fator que mais onera o custo de produção da cultura (Amado et al., 2002; Silva et al., 2005a; Duete et al., 2008). Para se obter altas produtividades é necessário o aporte de grandes quantidades de N. Quando utilizado, entretanto, em quantidades excessivas, o $\mathrm{N}$ pode ser perdido e, ao ser transferido para outros ecossistemas, converter-se em poluente de águas superficiais ou do lençol freático e da atmosfera (CANTARELLA, 2007).

O fertilizante nitrogenado mais utilizado no Brasil é a uréia, a qual pode ter a sua eficiência agronômica comprometida devido às perdas de $\mathrm{N}$ por volatilização. A recuperação do N-uréia variou de 17\% a 50\% (LARA CABEZAS; TRIVELIN, 1992; LARA CABEZAS et al., 2000; GAVA et al., 2001), enquanto que para o sulfato de amônio este índice foi de $70 \%$ (LARA CABEZAS et al., 2000). Em função disso e ainda, devido à presença de $\mathrm{S}$ na sua composição ( $24 \%$ de S), o sulfato de amônio pode ser um adubo bastante interessante para a cultura do milho.

Com relação ao $\mathrm{S}$, a adubação com esse nutriente muitas vezes é negligenciada no sistema de produção de milho (FANCELLI, 2010), com a agravante da disponibilidade desse elemento, em muitas áreas, ter diminuído nos últimos anos (RHEINHEIMER et al., 2005).

A deficiência em $\mathrm{S}$ ocorre, de forma mais freqüente, em solos arenosos e com baixos teores de matéria orgânica. Contudo, o uso continuado de fórmulas concentradas de adubos, associado ao cultivo intenso e com alto potencial produtivo, pode resultar em respostas das culturas à aplicação desse nutriente, mesmo em solos muito argilosos (ALVAREZ et al., 2007). Incrementos significativos na produtividade de grãos de milho foram observados com a adição de S (RHEINHEIMER et al., 2005; KHAN et al., 2006). Avaliando o comportamento de fontes de N para a cultura do milho, Lara Cabezas et al. (2005) e Lara Cabezas e Couto (2007) verificaram que o sulfato de amônio, em relação à uréia, proporcionou uma produtividade de milho superior, atribuindo os autores, como causa da resposta observada, ao S presente no sulfato de amônio.

A obtenção de altos rendimentos das culturas somente é possível quando todos os fatores de produção são manejados corretamente. Em função das peculiaridades de cada uma, as fontes de $\mathrm{N}$ podem tornar-se um fator importante no manejo da cultura do milho em semeadura direta. Assim, como objetivo principal, procurou-se avaliar os efeitos da adubação nitrogenada nessa gramínea, comparando-se as fontes uréia e sulfato de amônio em termos de 
produção de grãos e fornecimento de $\mathrm{N}$ e $\mathrm{S}$ para as plantas. Adicionalmente, com o objetivo de gerar informações para diagnose do estado nutricional do milho, uma vez que a análise química de $\mathrm{N}$ do solo é bastante limitada para prever a disponibilidade desse nutriente para as plantas, procurou-se através da diagnose foliar determinar a faixa de concentrações adequadas de $\mathrm{N}$ nas folhas.

\section{MATERIAL E MÉTODOS}

O experimento foi conduzido no município de Ribeirão Preto-SP, num solo classificado como Latossolo Vermelho distroférrico textura argilosa (Embrapa, 2006), apresentando na camada de 0 - 0,20 m os seguintes atributos químicos: $\mathrm{pH}\left(\mathrm{CaCl}_{2}\right)$ 5,5; matéria orgânica $=27 \mathrm{~g} \mathrm{dm}^{-3} ; \mathrm{P}$ (resina) $=14 \mathrm{mg} \mathrm{dm}^{-3} ; \mathrm{S}_{-} \mathrm{SO}_{4}=4 \mathrm{mg} \mathrm{dm}^{-3} ; \mathrm{K}=3,0$ $\mathrm{mmol}_{\mathrm{c}} \mathrm{dm}^{-3} ; \mathrm{Ca}=40 \mathrm{mmol}_{\mathrm{c}} \mathrm{dm}^{-3} ; \mathrm{Mg}=13 \mathrm{mmol}_{\mathrm{c}} \mathrm{dm}^{-3} ; \mathrm{H}+\mathrm{Al}=25 \mathrm{mmol}_{\mathrm{c}} \mathrm{dm}^{-3} ;$ saturação por bases $(\mathrm{V})=69 \%$. Tratava-se de uma área de primeiro ano de semeadura direta, sendo o experimento instalado após o cultivo de "milho safrinha". A análise química para fins de fertilidade do solo foi realizada segundo Raij et al. (1987). O S foi extraído utilizando-se a solução de fosfato monocálcico $0,01 \mathrm{~mol} \mathrm{~L}^{-1}$, conforme metodologia descrita por Cantarella e Prochnow (2001).

O delineamento experimental utilizado foi em blocos casualizados, segundo um esquema fatorial 5 x 2 (cinco doses de $\mathrm{N}$ e duas fontes de $\mathrm{N}$ ), com quatro repetições.

As doses de $\mathrm{N}$ empregadas na forma de uréia e sulfato de amônio foram: 0, 50, 100, 150 e $200 \mathrm{~kg} \mathrm{ha}^{-1}$ de N. As doses de $\mathrm{N}$ foram aplicadas parceladamente, com todas as parcelas (exceção ao tratamento testemunha - sem $\mathrm{N}$ ) recebendo uma adubação na semeadura com 20 $\mathrm{kg} \mathrm{ha}^{-1}$ de $\mathrm{N}$, sendo o restante da dose aplicada em cobertura quando as plantas apresentavam seis folhas completamente desenroladas.

As parcelas eram constituídas de seis linhas de 6,0 m de comprimento, espaçadas de 0,80 m, correspondendo uma área total de $28,8 \mathrm{~m}^{2}$ e uma área útil de $19,2 \mathrm{~m}^{2}$, pois se desprezou as linhas externas das parcelas, que representavam a bordadura. As unidades experimentais eram separadas por carreadores de 1,0 m de comprimento.

A semeadura do milho híbrido Dow AgroSciences 8480 foi realizada na segunda quinzena de novembro/2003, empregando-se seis sementes por metro linear, visando uma população final de 60 mil plantas $\mathrm{ha}^{-1}$. Todas as parcelas receberam uma adubação de semeadura com $90 \mathrm{~kg} \mathrm{ha}^{-1}$ de $\mathrm{P}_{2} \mathrm{O}_{5}$ e $60 \mathrm{~kg} \mathrm{ha}^{-1}$ de $\mathrm{K}_{2} \mathrm{O}$, empregando-se respectivamente como fontes o superfosfato simples e o cloreto de potássio.

Para a avaliação do estado nutricional, coletou-se de 20 plantas por parcela, por ocasião do aparecimento da inflorescência feminina (cabelo), a folha oposta e abaixo da 
espiga (MALAVOLTA et al., 1997). Determinou-se nas folhas as concentrações de nitrogênio e enxofre.

Para se estabelecer as concentrações adequadas de $\mathrm{N}$ na folha, utilizou-se metodologia semelhante à descrita por Coutinho et al. (1987), empregando-se as relações existentes entre as doses de $\mathrm{N}$, produtividade de grãos e concentrações de $\mathrm{N}$ nas folhas. Os limites superior e inferior da faixa de concentrações considerada adequada para esta gramínea foram associados, respectivamente, a máxima produtividade de grãos e a uma redução de $20 \%$ na mesma.

Com o objetivo de se avaliar a produção de grãos (umidade corrigida para $130 \mathrm{~g} \mathrm{~kg}^{-1}$ ), efetuou-se a colheita das plantas área útil de cada parcela.

O material vegetal foi preparado e analisado segundo Malavolta et al. (1997).

Os dados foram submetidos à análise de variância e quando o teste $\mathrm{F}$ era significativo a 5\%, procedeu-se ao ajuste de regressões utilizando o pacote estatístico Sigma Plot.

\section{RESULTADOS E DISCUSSÃO}

Verifica-se na Figura 1 que a adubação nitrogenada proporcionou aumentos significativos na produtividade de grãos $(\mathrm{F}=136,2 * *)$, sendo que, com a adição de 50, 100, 150 e $200 \mathrm{~kg} \mathrm{ha}^{-1}$ de $\mathrm{N}$ obtiveram-se acréscimos médios na produção em relação à testemunha (sem N) de respectivamente 65, 162, 170 e 164\%. A importância da adubação nitrogenada para a cultura do milho também foi demonstrada em trabalhos conduzidos por Lara Cabezas et al. (2005), Silva et al. (2005a), Lara Cabezas e Couto (2007) e Duete et al. (2008).

Chamou a atenção o menor desenvolvimento das plantas do tratamento testemunha ( sem $\mathrm{N}$ ), com a exibição, principalmente a partir do estádio V6, de sintomas clássicos de carência de N. Em função disso, acredita-se que o aumento na produtividade proporcionado pela aplicação de $\mathrm{N}$ foi devido ao incremento na área foliar, proporcionando uma maior síntese de fotoassimilados - isso pelo fato deste nutriente ser constituinte da molécula de clorofila, atuando nos processos de divisão e expansão celular (VARVEL et al., 1997; MENGEL; KIRKBY, 2001). 


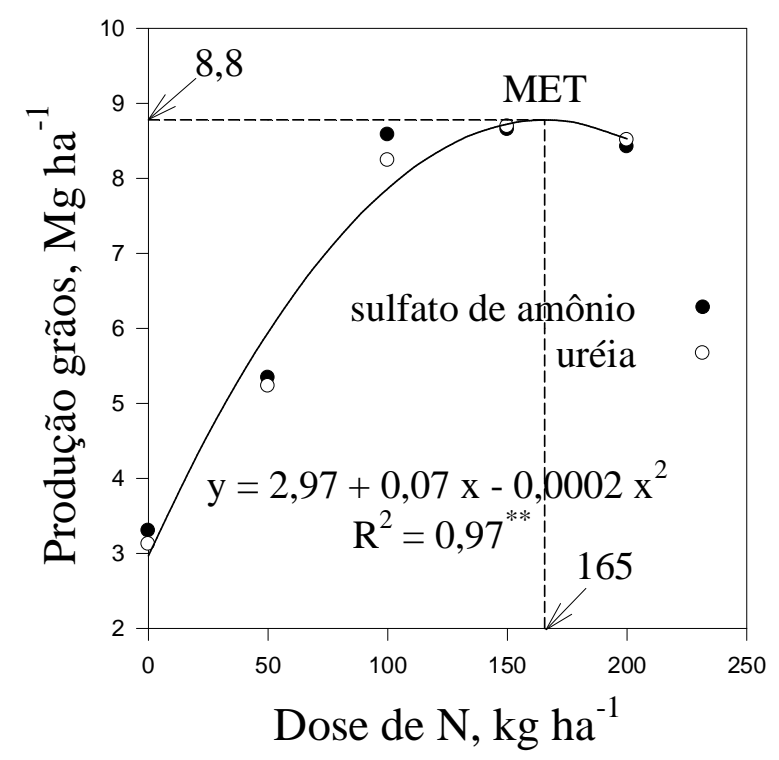

Figura 1. Produtividade de grãos de milho em função da adubação nitrogenada com uréia e sulfato de amônio.

Efetuando-se a derivada primeira da equação de segundo grau apresentada na Figura 1, calculou-se a dose de $\mathrm{N}$ que proporcionou a maior produtividade de grãos. Essa máxima eficiência técnica (MET) foi obtida com a dose de $165 \mathrm{~kg} \mathrm{ha}^{-1}$ de $\mathrm{N}$, correspondendo uma produção de $8,8 \mathrm{Mg} \mathrm{ha}^{-1}$ de grãos de milho. Quando se considera a classe de resposta esperada ao nitrogênio como sendo alta e, produtividade de grãos dentro da faixa de 8 a 10 $\mathrm{Mg} \mathrm{ha}^{-1}$, essa dose de $\mathrm{N}$ está um pouco acima daquela recomendada para a cultura do milho no estado de São Paulo (RAIJ et al., 1996). Apesar de terem obtido uma produtividade de grãos inferior, Silva et al. (2005b) obtiveram a MET com dose próxima a observada nesse trabalho.

Para a produção de grãos ainda, não se verificou diferença significativa entre as fontes de $\mathrm{N}\left(\mathrm{F}=0,28^{\mathrm{NS}}\right)$, sendo também não significativa a interação doses $\mathrm{x}$ fontes de $\mathrm{N}(\mathrm{F}=$ $0,16^{\mathrm{NS}}$ ). Esse fato chama a atenção, uma vez que Lara Cabezas et al. (2005) verificaram que a fonte de $\mathrm{N}$ exercia uma influência maior que a época de aplicação desse nutriente, com o sulfato de amônio sendo significativamente superior à uréia (LARA CABEZAS et al. , 2005; LARA CABEZAS ; COUTO, 2007). Aumentos significativos na produtividade de grãos de milho também foram observados com a adição de $S$ por Rheinheimer et al. (2005) e Khan et al. (2006).

Chama a atenção, o fato da presença de $S$ no sulfato de amônio não ter contribuído para o aumento de produção de grãos, uma vez que o solo apresentava, de acordo com Raij et al. (1996), um baixo teor de $\mathrm{S}_{-} \mathrm{SO}_{4}$. Na literatura, entretanto, existem controvérsias sobre a interpretação dos níveis de suficiência desse nutriente no solo, uma vez que essa definição foi 
realizada com poucos experimentos, inclusive com alguns deles realizados em casa de vegetação (RHEINHEIMER et al., 2005).

Quando a uréia é aplicada na superfície do solo, sem incorporação, as perdas de amônia por volatilização são mais intensas, isto devido a pequena possibilidade da amônia, uma vez volatilizada, ser retida pelo solo em outro ponto de menor valor $\mathrm{pH}$ e com menores concentrações de amônia (CANTARELLA, 2007). Esse fato poderia ter contribuído para uma menor eficiência dessa fonte em relação ao sulfato de amônio, o qual é um adubo pouco susceptível à volatilização de amônia em solo ácido (LARA CABEZAS et al., 1997b; CANTARELLA, 2007).

Essas perdas de N-uréia, entretanto, são governadas por um grande número de fatores que interagem entre si, não sendo surpreendente que os experimentos apresentem resultados variáveis, encontrando-se desde perdas de amônia por volatilização menores que 10\% (SHANKARACHARYA; MEHTA, 1971) a perdas superiores a 50\% (RODRIGUES; KIEHL, 1986; LARA CABEZAS et al., 1997b).

Segundo Shankaracharya e Mehta (1971), as perdas de amônia provenientes da uréia podem ser drasticamente reduzidas, se antes de completar a hidrólise, o fertilizante for localizado abaixo da superfície do solo, através do movimento descendente da uréia recémaplicada, promovido pela água de irrigação ou de chuva. Neste sentido, Terman (1979) e Hargrove (1988) verificaram em áreas de solo descoberto que 10 a $20 \mathrm{~mm}$ de chuva ou irrigação eram suficientes para incorporar a uréia ao solo. Uma precipitação de $10 \mathrm{~mm}$, entretanto, pode não ser suficiente para eliminar a volatilização de amônia no sistema semeadura direta (SSD). Assim, Lara Cabezas et al. (1997a) quantificaram perdas substanciais de amônia em área de milho em SSD, mesmo após a irrigação com $28 \mathrm{~mm}$ de água realizada após a aplicação da uréia.

Embora não exista concordância sobre a quantidade de chuva necessária para reduzir de maneira significativa as perdas de N-uréia, acredita-se que o comportamento similar das fontes de $\mathrm{N}$ nesse trabalho, pode ser parcialmente atribuído à precipitação pluvial de $14 \mathrm{~mm}$ ocorrida três dias após a aplicação dos fertilizantes nitrogenados.

Outra questão que pode ajudar a explicar a não diferença entre as fontes de $\mathrm{N}$ é que se a concentração de amônia no ar estiver alta, o ponto de compensação de amônia da planta pode ser negativo, podendo assim, ocorrer a absorção de $\mathrm{NH}_{3}$ da atmosfera (FARQUHART et al., 1980). Tem sido verificado que plantas adubadas com fontes de $\mathrm{N}$ sujeitas à volatilização de amônia, podem recapturar quantidades significativas do $\mathrm{N}$ perdido para o ar atmosférico (FENILLI et al., 2007). 
Os resultados desse experimento corroboram levantamento realizado por Cantarella e Raij (1986), os quais reuniram dados de dezenas de experimentos realizados em condições de campo no estado de São Paulo e observaram que, em termos de produção, em nenhum deles ocorreram diferenças significativas entre a uréia e outras fontes de $\mathrm{N}$.

Verifica-se na Figura 2 que a adubação nitrogenada aumentou significativamente as concentrações de $\mathrm{N}$ nas folhas $\left(\mathrm{F}=102,2^{* *}\right)$. As fontes desse nutriente comportaram-se de maneira semelhante $\left(F=0,59^{\mathrm{NS}}\right)$, sendo também não significativa a interação doses $\mathrm{x}$ fontes $\left(\mathrm{F}=0,57^{\mathrm{NS}}\right)$. No tocante às concentrações de $\mathrm{S}$ nas folhas, observou-se que a interação dose de $\mathrm{N} x$ fontes foi significativa $(\mathrm{F}=12,97 * *)$, sendo o desdobramento dessa interação apresentado na Figura 2. Devido à presença de $\mathrm{S}$ na sua constituição, o sulfato de amônio aumentou de maneira linear as concentrações desse nutriente na planta. Os teores de $\mathrm{S}$ nas folhas estão dentro da faixa de suficiência sugerida por Malavolta et al. (1997), mesmo nas plantas que não receberam na adubação esse nutriente.
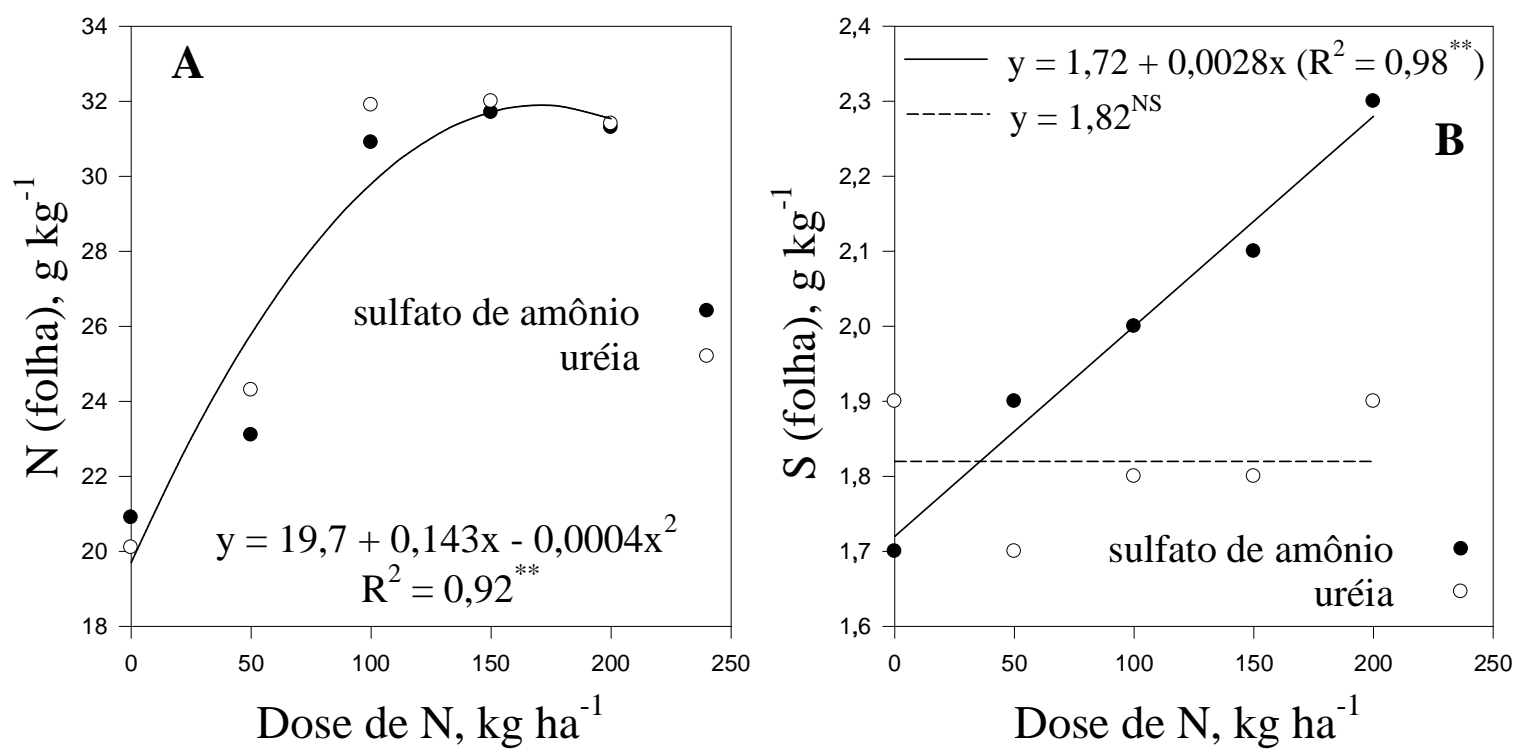

Figura 2. Concentrações de nitrogênio (A) e enxofre (B) nas folhas de milho em função da adubação nitrogenada com uréia e sulfato de amônio.

É importante destacar, que o metabolismo do $\mathrm{N}$ e do S estão diretamente relacionados. Koprivova et al. (2000) relataram que as assimilações de N e S são bem coordenadas e, a deficiência de um deles pode afetar a via de assimilação do outro. Neste sentido, Fismes et al. (2000), em condições de campo, verificaram que a deficiência de $\mathrm{N}$ reduziu a eficiência de utilização de S (EUS). No presente experimento, tal fato não foi constatado, uma vez que sintomas de deficiência de $\mathrm{N}$ foram verificados nas plantas do tratamento testemunha (sem $\mathrm{N}$ ), mas o fornecimento de $\mathrm{N}$ na forma de uréia (adubo sem $\mathrm{S}$ ) não alterou a assimilação de $\mathrm{S}$, 
uma vez que as concentrações desse nutriente na planta não foram significativamente afetadas.

As plantas que não receberam a aplicação de $\mathrm{N}$ apresentaram sintomas de deficiência desse nutriente, caracterizados por uma clorose em "V" invertido, começando nas folhas mais velhas, caminhando do ápice em direção à base ao longo da nervura principal, até tomar a folha toda. Por ocasião do aparecimento da inflorescência feminina, essas plantas apresentavam, na folha oposta e abaixo da espiga, concentrações de $\mathrm{N}$ inferiores a $23,0 \mathrm{~g} \mathrm{~kg}^{-1}$.

A interpretação dos resultados da análise foliar é feita pela comparação dos valores encontrados na amostra colhida com técnicas bem padronizadas, com níveis críticos ou faixa de teores foliares considerada adequada para uma espécie vegetal. Esses valores podem variar de acordo com vários fatores, a saber: a época e o procedimento de coleta de amostras, o potencial produtivo da lavoura, a eficiência do cultivar, clima, práticas culturais, etc (MALAVOLTA et al., 1997; ALVAREZ V. et al., 2007). Além disso, para a cultura do milho, os teores de nutrientes considerados adequados sugeridos por Malavolta et al. (1997) foram definidos com base na literatura internacional, utilizando dados dessa gramínea cultivada no sistema plantio convencional. Assim, é bastante sugestivo proceder à calibração da faixa de suficiência para o $\mathrm{N}$, em consonância com as nossas condições e para a nova realidade dessa cultura, ou seja, o cultivo em sistema semeadura direta.

Utilizando-se a equação do segundo grau apresentada na Figura 1, calcularam-se as doses de $\mathrm{N}$ que corresponderam à máxima produção de grãos e a uma redução de $20 \%$ na mesma, substituindo-se estes valores de " $x$ " na equação de regressão quadrática que definiu as relações existentes entre as doses de $\mathrm{N}$ empregadas na adubação e suas concentrações nas folhas (Figura 2). Os valores assim obtidos (concentrações de $\mathrm{N}$ ), 31,9 e 28,0 $\mathrm{g} \mathrm{kg} \mathrm{k}^{-1}$ corresponderam, respectivamente, ao limite superior e inferior da faixa de concentrações de $\mathrm{N}$ considerada adequada para esta gramínea. Essas concentrações de $\mathrm{N}$ estiveram associadas, respectivamente, às doses de $165 \mathrm{e} 75 \mathrm{~kg} \mathrm{ha}^{-1} \mathrm{de} \mathrm{N}$, correspondendo às produtividades de grãos de milho respectivamente de 8,8 e 7,0 $\mathrm{Mg} \mathrm{ha}^{-1}$. Os teores considerados adequados por Malavolta et al. (1997) estão dentro de uma faixa mais ampla $\left(27,5-32,5 \mathrm{~g} \mathrm{~kg}^{-1}\right)$, porém não muito diferente daquela estabelecida nesse trabalho.

\section{CONCLUSÃO}

A adubação nitrogenada aumentou a produtividade de grãos de milho $\mathrm{e}$ as concentrações de $\mathrm{N}$ na planta, sem, contudo, existir diferença significativa entre as fontes de $\mathrm{N}$ utilizadas (uréia e sulfato de amônio). 
As concentrações de $\mathrm{N}$ nas folhas consideradas adequadas estão dentro do intervalo de 28,0 a $31,9 \mathrm{~g} \mathrm{~kg}^{-1}$.

\section{REFERÊNCIAS}

ALVAREZ V., V.H. et al. (Eds.) Fertilidade do solo. Viçosa: Sociedade Brasileira de Ciência do Solo, 2007. p.595-644.

AMADO, T.J.C.; MIELNICZUK, J.; AITA, C. Recomendação de adubação nitrogenada para o milho no RS e SC adaptada ao uso de culturas de cobertura do solo, sob plantio direto.

Revista Brasileira de Ciência do Solo, v.26, p.241-248, 2002.

CANTARELLA, H. Nitrogênio. In: NOVAIS, R.F.et al. (Eds.) Fertilidade do solo. Viçosa: Sociedade Brasileira de Ciência do Solo, 2007. p.375-470.

CANTARELLA, H.; PROCHNOW, L. I. Determinação do sulfato em solos. In: RAIJ, B. Van et al. (Eds.) Análise química para avaliação da fertilidade de solos tropicais. Campinas: Instituto Agronômico, 2001. p.225-230.

CANTARELLA, H.; RAIJ, B. van Adubação nitrogenada no estado de São Paulo. In: SANTANA, M.B.M. (Ed.) Adubação nitrogenada no Brasil. Ilhéus: CEPLAC/SBCS, 1986. p.47-79.

COUTINHO, E.L.M.et al. Diagnose da nutrição fosfatada na cultura do sorgo sacarino. Pesquisa Agropecuária Brasileira, v.22, p.451-457, 1987.

DUETE, R.R.C.et al. Manejo da adubação nitrogenada e utilização do nitrogênio $\left({ }^{15} \mathrm{~N}\right)$ pelo milho em Latossolo Vermelho. Revista Brasileira de Ciência do Solo, v.32, p.161-171, 2008.

EMBRAPA. EMPRESA BRASILEIRA DE PESQUISA AGROPECUÁRIA. Centro Nacional de Pesquisa de Solos. Sistema brasileiro de classificação de solos. 2.ed. Rio de Janeiro, 2006. 306p.

EPSTEIN, E.; BLOOM, A.J. Nutrição mineral de plantas: Princípios e perspectivas, 2 ed. 2006. Ed. Planta. 401 p.

FANCELLI, A.L. Boas práticas para uso eficiente de fertilizantes na cultura de milho. Informações Agronômicas, Piracicaba: IPNI, n.131, p.1-16, 2010.

FARQUHAR, G.D.et al. On the gaseous exchange of ammonia between leaves and the environment: determination of the ammonia compensation point. Plant Physiology, v.66, p.710-714, 1980.

FENILLI, T.A.B.et al. Volatilization of ammonia derived from fertilizer and its reabsorption by coffee plants. Communications in Soil Science and Plant Analysis, v.38, p.1741-1751, 2007. 
FISMES, J.et al. Influence of sulfur on apparent N-use efficiency, yield and quality of oilseed rape (Brassica napus L.) grown on a calcareous soil. European Journal of Agronomy, v.12, p.127-141, 2000.

GAVA, G.J.et al. Crescimento e acúmulo de nitrogênio em cana-de-açúcar cultivada em solo coberto com palhada. Pesquisa Agropecuária Brasileira, v.36, p.1347-1354, 2001.

HARGROVE, W.L. Soil, environmental, and management factors influencing ammonia volatilization under field conditions. In: BOCK, B.R.; KISSEL, D.E. (Eds.) Ammonia volatilization from urea fertilizers. Muscle Shoals, National Fertilizer Development Center. Tenessee Valley Authority, 1988. p.17-36.

KHAN, M.J.et al. Response of maize to different levels of sulfur. Communications in Soil Science and Plant Analysis, v.37, p.41-51, 2006.

KOPRIVOVA, A.et al. Regulation of sulfate assimilation by nitrogen in Arabidopsis. Plant Physiology, v.122, p.737-746, 2000.

LARA CABEZAS, W.A.R.et al. Imobilização de nitrogênio da uréia e do sulfato de amônio aplicado em pré-semeadura ou cobertura na cultura de milho no sistema plantio direto.

Revista Brasileira de Ciência do Solo, v.29, p.215-226, 2005.

LARA CABEZAS, W.A.R.; COUTO, P.A. Imobilização de nitrogênio da uréia e do sulfato de amônio aplicado em pré-semeadura ou cobertura na cultura de milho, no sistema plantio direto. Revista Brasileira de Ciência do Solo, v.31, p.739-752, 2007.

LARA CABEZAS, W.A.R.; KORNDÖRFER, G.H.; MOTTA, S.A. Volatilização de N-NH na cultura de milho: I. Efeito da irrigação e substituição parcial da uréia por sulfato de amônio. Revista Brasileira de Ciência do Solo, v.21, p.421-487, 1997a.

LARA CABEZAS, W.A.R.; KORNDÖRFER, G.H.; MOTTA, S.A. Volatilização de N-NH na cultura de milho: II. Avaliação de fontes sólidas e fluídas em sistema de plantio direto e convencional. Revista Brasileira de Ciência do Solo, v.21, p.489-496, 1997b.

LARA CABEZAS, W.A.R.; TRIVELIN, P.C.O. Efeito do tamanho de grânulo e relação N/S da uréia aplicada em superfície na volatilização de amônia sob diferentes umidades iniciais do solo. Revista Brasileira de Ciência do Solo, v.16, p.409-413, 1992.

LARA CABEZAS, W.A.R.et al. Balanço da adubação sólida e fluída de cobertura na cultura do milho, em sistema plantio direto no triângulo mineiro (MG). Revista Brasileira de Ciência do Solo, v.24, p.363-376, 2000.

MALAVOLTA, E.; VITTI, G.C.; OLIVEIRA, S.A. Avaliação do estado nutricional das planta: princípios e aplicações. 2.ed. Piracicaba: POTAFOS, 1997. 319p.

MENGEL, K.; KIRKBY, E.A. Principles of plant nutrition. 5. ed. Dordrecht: Kluver Academic Publishers, 2001.

RAIJ, B. van.et al. Recomendações de adubação e calagem para o Estado de São Paulo. Campinas, 1996. 285p. (Boletim Técnico, 100). 
RAIJ, B. van.et al. Análise química do solo para fins de fertilidade. Campinas: Fundação Cargill, 1987. 170p.

RHEINHEIMER, D.S.et al. Resposta de culturas à aplicação de enxofre e a teores de sulfato num solo de textura arenosa sob plantio direto. Ciência Rural, v.35, p.562-569, 2005.

RODRIGUES, M.B.; KIEHL, J.C. Volatilização de amônia após emprego de uréia em diferentes doses e modos de aplicação. Revista Brasileira de Ciência do Solo, v.10, p.37-43, 1986.

SHANKARACHARYA, N.B.; MEHTA, B.V. Note on the losses of nitrogen by volatilization of ammonia from loamy-sand soil of Anand treated with different $\mathrm{N}$ carriers under field conditions. Indian Journal Agriculture Science, v.41, p.131-133, 1971.

SILVA, E.C. et al. Doses e épocas de aplicação de nitrogênio na cultura do milho em plantio direto sobre Latossolo Vermelho. Revista Brasileira de Ciência do Solo, v.29, p.353-362, 2005a.

SILVA, E.C.; BUZETTI, S.; LAZARINI, E. Aspectos econômicos da adubação nitrogenada na cultura do milho em sistema de plantio direto. Revista Brasileira de Milho e Sorgo, v.4, p.286-297, 2005b.

TERMAN, G.L. Volatilization losses of nitrogen as ammonia from surface-applied fertilizers, organic amendments, and crop residues. Advanced Agronomy, v.31, p.189-223, 1979.

VARVEL, G.E.; SCHPERS, J.S.; FRANCIS, D.D. Ability for in-season correction of nitrogen deficiency in corn using chlorophyll meters. Soil Science Society of America Journal, v.61, p.1233-1239, 1997. 
